\title{
CONSIDERAÇÕES SOBRE A QUESTÃO DA TÉCNICA A PARTIR DO SEMINÁRIO DE LE THOR DE MARTIN HEIDEGGER
}

\author{
Manuela Santos Saadeh ${ }^{1}$
}

\begin{abstract}
Resumo
Os quatro seminários de Thor de Heidegger se configuram como um estudo da história da Metafísica em suas transformações mais fundamentais. Neles, o filósofo começa por mostrar a história da Metafísica resumidamente do seu princípio ao seu ocaso. Neste artigo, o foco é precisamente o de problematizar a questão de saber como e porque Heidegger ensina que a partir da concepção - implicitamente enviada ao longo de dois mil e quinhentos anos de pensamento filosófico - do Ser enquanto a entidade do ente, o Ser ele mesmo, o Um, se tornou finalmente a técnica moderna a partir dos desdobramentos históricos do pensamento ocidental, a Metafísica.
\end{abstract}

Palavras-chave: Heidegger, História, Metafísica, Fenomenologia, Ciência.

\section{CONSIDERATIONS ON THE QUESTION OF TECHNIQUE FROM MARTIN HEIDEGGER'S LE THOR SEMINAR}

\begin{abstract}
Heidegger's four seminars of Le Thor, are configured as a study of the history of metaphysics in its most fundamental transformations. In them, the philosopher begins by showing the history of metaphysics in brief from its beginning to its demise. In this article, the focus is precisely to problematize the question of how and why Heidegger teaches that from the conception - implicitly sent over two and a half thousand years of philosophical thought - of the Being as the entity of the being, the Being he even, the One, finally became the modern technique from the historical developments of Western thought, Metaphysics.
\end{abstract}

Keywords: Heidegger, Metaphysics, History, Phenomenology, Science.

1 Pós-doutoranda em Filosofia pela UFRJ. Doutora em Filosofia pela Universidade Federal do Rio de Janeiro (2019). Mestre em Filosofia também pela UFRJ (2014). Pós-graduada em Filosofia Antiga pela Pontifícia Universidade Católica do Rio de Janeiro (2013). Bacharel em Filosofia pela UNISUL (2016). Tem experiência no âmbito do estudo da Filosofia com ênfase na História da Filosofia e na Filosofia de Martin Heidegger. Contato: santosmanuela0@ gmail.com. http://orcid.org/0000-0003-3707-1921 
Nesse pensamento, entabulado no final de sua vida, Heidegger não fez mudanças de direção da questão desde Ser e Tempo, mas, ao contrário, permanece na mesma direção. Ocorre que alterar questões que ficaram insuficientes em Ser e Tempo, só pode fazer descobrir outras.

A questão fundamental para o filósofo, é e sempre foi a de pensar como o Ser é totalmente interpelado por respeito ao ente, isto é, por respeito ao presente, que o é enquanto histórico. Se a História enquanto Metafísica se determina como a concepção sempre implícita do Ser enquanto entidade do ente, isto é, enquanto esta forma subsistente para o Ser como pano de fundo para todas concepções filosófico-históricas fundamentais acerca do Ser - $1 \delta \varepsilon ́ \alpha$ (ideia), ov̉oía (ousia), essentia-subitantia, sujeito, mônada, consciência absoluta, vontade -, isto se dá porque sempre o pensamento já esteve se perguntando pelo Ser enquanto fundamento formal do ente. Contudo, lá quando a questão foi primeiramente posta entre os

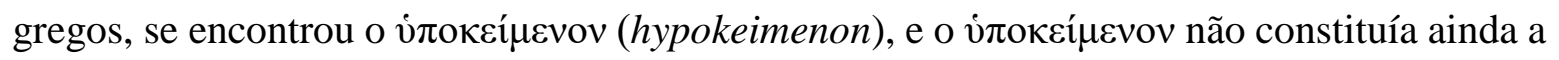
entidade, mas a presença do ente, isto é, a presença aludida do ente. Já no final do pensamento

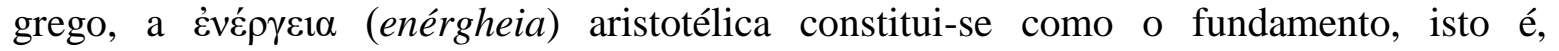
propriamente quando manifesta-se o começo da História do Ser enquanto a entidade do ente.

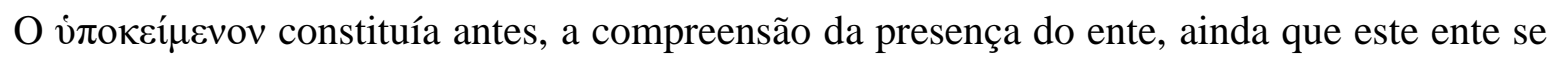
apresente a partir dele mesmo enquanto fenômeno, na sua reserva própria. Como um exemplo disso, posso tomar esta arvore aqui a minha frente e observar que ela se faz ver, mas não se faz ver oferecida (conceituada): é simplesmente a forma do fenômeno se dar. Quando a


mas essa reserva dela nela mesma se esmaece em benefício de sua exibição, da explanação no $\lambda$ ó $о$ os (logos). Heidegger nos diz (2002, p. 312):

\footnotetext{
Aristóteles explica este "de...para...” no Livro 5 [da Física], Capítulo 1: O Ser do



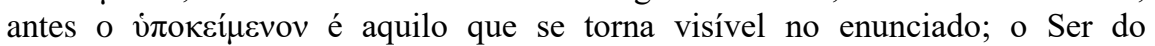

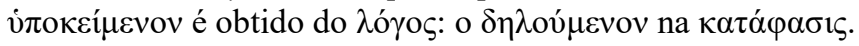

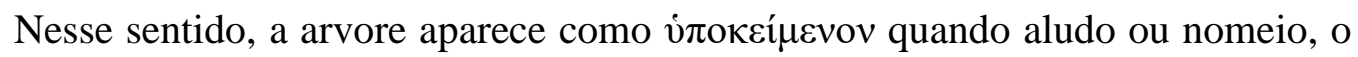
que quer dizer que ainda não estou tirando dela o caráter de fenômeno, isto é, não estou intervindo nela diretamente como o que salienta para ela aparecer, como acontece no enunciado. É fenômeno porque nada ainda foi dito sobre ela. Nosso pensamento comum diz 
“arvore” sem pensar que há uma consciência por trás pondo arvore e, no entanto, já pensamos arvore em geral dentro de uma perspectiva prévia de sentido de Natureza, configurado, fundamentalmente desde a metafísica da subjetividade (século XVI), enquanto representação. Mas essa forma do sentido de Natureza, a do pensamento enquanto


uma forma de "representação", mas não ainda na forma da consciência subjetiva, era apenas uma mediação no $\lambda$ ó $\gamma$ os; tem de haver uma unificação do ente com a linguagem, pelo menos pela nomeação.

Já a configuração moderna do Ser enquanto o Sujeito, podemos pensar conjuntamente com Heidegger, surgiu da necessidade do pensamento cartesiano de transformar a verdade em certeza para lograr um fundamento que fosse indubitável, indiscutível. Embora o pensamento grego já tivesse a questão da obtenção de um fundamento,


seu fundamento. Tal prova passou a ser requerida porque o pensamento exigiu ${ }^{2}$, na Modernidade, garantir, através da verdade enquanto certeza, o controle do verdadeiro. Isso porque já havia uma movimentação implícita pensante de possibilitação do estabelecimento do a priori como fundação do fundamento. Ocorre que este a priori se estabeleceu por conta de uma transformação no sentido da disponibilidade que, para Heidegger, vem sendo implicitamente no pensamento filosófico desde os gregos, e que foi sobreposto à Natureza.


concebida sob a requisição do sentido implícito da disponibilidade. Heidegger ensina (1997, p. 210):

Esta [a ov̉øía] significa o Ser no sentido da presença permanente e consistente, da disponibilidade, da objetividade dada (Vorhandenheit) [subsistência]. O ente propriamente dito é, por conseguinte, o ente-permanente (-s Immer-Seiende), ḋeí òv. Constante e consistentemente presente é aquilo a que, de antemão, em toda a

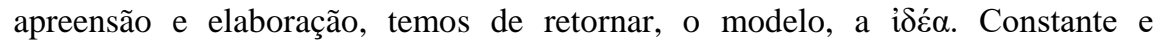
consistentemente presente é aquilo que, em cada $\lambda o ́ \gamma o \varsigma$, enunciado, temos de



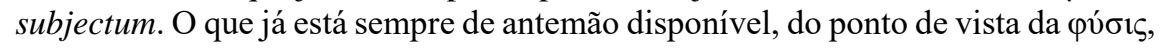

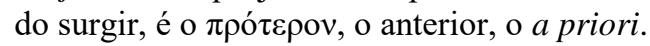

2 A condição de possibilidade de uma tal exigência se manifesta propriamente enquanto a História da Metafísica desde Platão.

\begin{tabular}{|c|c|c|c|c|}
\hline Qevista Dialectus & Ano 10 & n. 23 & Maio - Agosto 2021 & p. $210-230$ \\
\hline
\end{tabular}


A partir do final do medievo, este sentido implícito do Ser enquanto disponibilidade se converte em incondicionalidade, por conta de uma interpretação do sentido da disponibilidade (do Ser) que passa a ter a forma da espontaneidade (subjectum), atendendo já a uma nova reivindicação do pensamento. Para Heidegger, quando a verdade deixa, desde os gregos, de ser considerada como abertura, desocultar, a transformação do sentido de verdade em veritas, ficou reduzida à ideia de adequatio. "A mudança da metafísica

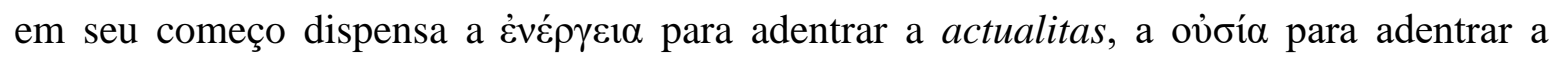

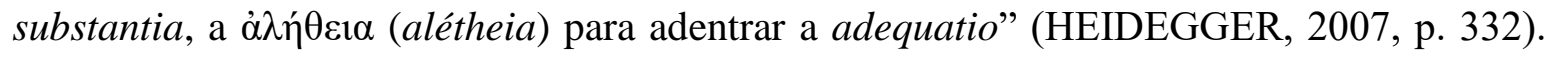

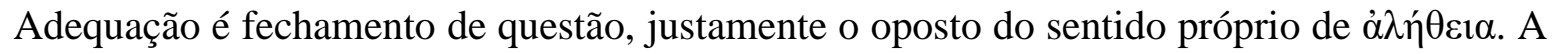
partir dessa transformação da forma lógica da verdade, toda interpretação passou também a ganhar uma nova configuração. Então a disponibilidade enquanto o sentido do Ser que, para Heidegger, foi implicitamente pressuposto pelos gregos na presença da $\varphi v ́ \sigma ı \varsigma$, passou a ser pressuposta como a disponibilidade da incondicionalidade (Sujeito), e com isso se colocou a base para a ideia moderna de liberdade, que se tornou o sentido de incondicionalidade. Mas o que vem a ser propriamente a disponibilidade?

Para o filósofo, a disponibilidade, implicitamente pensada pelos gregos, põe o ente na perspectiva do produtor produzível. Heidegger postula (2012, p 161):

\begin{abstract}
Produzir [preparar] significa ao mesmo tempo, porém: trazer para a esfera mais estreita ou mais ampla daquilo que é acessível, para cá para o aí, de tal modo que o produzido se encontra nele mesmo por si e, como algo por si constante, permanece, previamente encontrável e se acha diante de nós. Aquilo que se encontra diante de nós de início e constantemente na esfera das posturas comportamentais humanas e, de acordo com isto, se mostra como constantemente disponível, é o todo das coisas de uso, com as quais temos incessantemente de lidar, o todo das coisas que são, as quais são inseridas segundo o seu próprio sentido em uma relação mútua, o utensílio utilizado e os frutos constantemente gerados pela natureza: casa e corte, floresta e campo, luz e calor. Aquilo que se acha assim presente à vista [subsistente] é considerado pela experiência cotidiana como ente em primeira linha.
\end{abstract}

O ente é a concretude produtiva; isto quer dizer que já há aqui uma forma absolutamente implícita de compreensão da presença imediata do ente (do seu Ser) pela perspectiva da produção, que corresponde à forma fundamental do Dasein enquanto lida, curadoria. Em função desta perspectiva da produção a partir do sentido primário de disponibilidade para o Ser é que, para Heidegger, ocorreram todas essas transformações do sentido do Ser (como entidade do ente) na História da Metafísica. No fim desta história, o

\begin{tabular}{|l|l|l|l|l|}
\hline Revista Dialectus & Ano 10 & n. 23 & Maio - Agosto 2021 & p. $210-230$ \\
\hline
\end{tabular}


sentido de disponibilidade passa a ser o de incondicionalidade, e esta aparece como fundamentação para o fundamento, porque na incondicionalidade institui-se um sujeito enquanto o fundamento incondicional. Heidegger diz (2007, p. 225):

O deslocamento da composição estrutural essencial da antiga representação consiste no fato de o trazer-para-diante-de-si re-presentador de tudo aquilo que vem ao encontro estabelecer a si mesmo como o Ser do ente. A constância daquilo que se presenta, isto é, entidade, consiste agora na representidade por meio e para esse re-presentar, isto é, nesse re-presentar mesmo. Antes disso, todo ente é subjectum, ou seja, algo que se encontra aí defronte por si mesmo. É somente por isso que ele

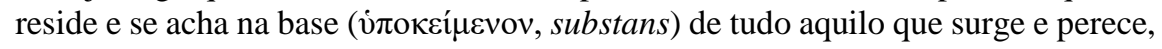
isto é, de tudo aquilo que ganha o Ser e que dele se despede. Em toda metafísica a entidade do ente é subjetividade em sentido originário. A mística medieval traduz subjectum e substantia por "understand" e, de maneira correspondentemente literal, obiectum por "gegenwurf" (o contrajogado). No começo da modernidade, a entidade do ente se transforma. [...] O homem torna-se um ente insigne (subjectum), isto é, "sujeito decidido". [..] A subjetividade em sentido moderno é contrastada com a substancialidade e, por fim, esta substancialidade é suprimida nela.

O Sujeito Moderno enquanto a nova forma da entidade do ente metafísica (o Ser), se configura como uma transformação do subjectum que, no Medievo, era simplesmente o

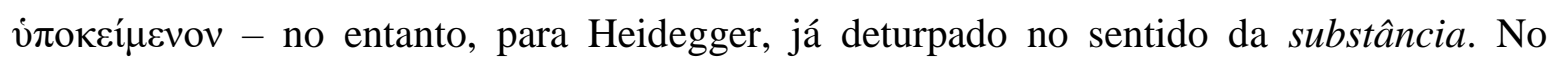
pensamento medieval, a substância foi interiorizada não só no ente como seu elemento último, mas como elemento interno do próprio fundamento, uma vez que na verdade requerida como certeza, a única certeza que Descartes encontrou foi o pensamento. Não por uma não "evolução" do pensamento, mas a questão da fundamentação do fundamento não tinha sido colocada na Antiguidade porque, para Aristóteles, certamente seria estapafúrdio pedir a fundamentação do fundamento: este já é, já está dado. A mudança da verdade em veritas implicitamente mudou a questão, porque surge o sentido de uma concordância por respeito à verdade. "A Alétheia, enquanto clareira de presença e a presentificação no pensar e dizer, logo desemboca na perspectiva da adequação, no sentido da concordância entre o representar e o que se presenta" (HEIDEGGER, 1996, p. 107). Se há concordância, então o fundamento tem que aparecer concordado com sua fundamentação. A verdade não pode simplesmente se dar como uma evidência, ou como uma verdade dada por consenso. Para Descartes, o verdadeiro tinha que se provar verdadeiro, enquanto que, para Aristóteles, não era possível pedir o fundamento, uma prova do princípio, pois, como dissemos anteriormente, 


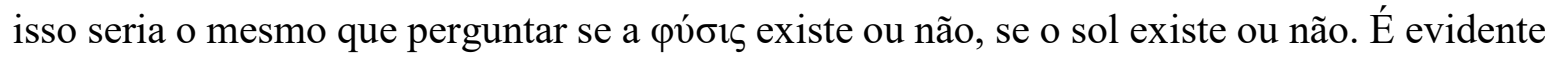
que a pv́oıs é. Contudo, a Modernidade com sua dúvida, ousou fazer essa pergunta.

A partir da mudança da verdade em veritas, já haviam se transformado as possibilidades das perguntas, das questões por respeito ao Ser. Um enrijecimento lógico foi se tornando manifesto, pois se a verdade enquanto veritas está ligada à adequatio, à adequação, isso faz com que o pensamento comece a inquirir todo Ser de forma totalmente


porque a Lógica pode perguntar qual é a concordância de que há em um ser de verdade. Descartes duvidou disso com muita propriedade ao dizer: se posso estar dormindo, em sonhos, dentro de um contexto que não existe, por que não posso dizer que agora estou dentro de um contexto ( $\varphi v ́ \sigma ı \varsigma)$ que não existe? Mesmo que você me espete, eu digo que posso estar sonhando que estou sendo espetada, porque posso sonhar tudo. Ele também poderia estar sonhando que está pensando; contudo sonhando ou não, sou eu que estou sonhando/pensando. $\mathrm{O}$ eu, o sujeito, se torna quase que imediatamente o fundamento, o próprio Ser. Com isso Descartes encontrou um lugar para a certeza e todo o fundamento para o sujeito que aparece e se oferece como fundamento da certeza e de todo o real, não sendo

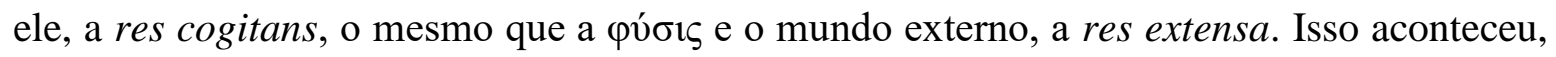
prediz Heidegger, em função da possibilidade da mudança de perspectiva da disponibilidade apreendida implícita e imediatamente no ente da lida. Na era Moderna, o pensamento exigiu a incondicionalidade na disponibilidade, e a partir dessa incondicionalidade surgiu a possibilidade de fundar o Ser no homem, no próprio Sujeito. Só seria fundamento para a Filosofia Moderna o fundamento que fosse sem condição - incondicional, portanto. Assim, tal Filosofia entendeu a possibilidade do a priori no sentido de ser $o$ incondicional. Na Antiguidade, o a priori tem o sentido de ser o ponto de partida apenas; o عĩoo $\zeta$ aristotélico é o a priori, mas ele não se oferece como incondicional. Para os gregos, ao contrário, esse experimento do ente na sua fenomenalidade direta é totalmente concreto. A primeira verdade é de que o ente aparece enquanto aquilo que ele é. A montanha aparece enquanto montanha porque ela já aparece reportada ao $\lambda o ́ \gamma o \varsigma$ enquanto tal, nomeada. Ente é fenômeno, $\alpha \lambda \eta \dot{\eta} \theta \varepsilon 1 \alpha$ (alétheia). Fenômeno é o que é ainda livre de qualquer atribuição de juízo: algo que para o pensamento moderno, é impossível. Para este o ente só é se se der já em uma representação; para o pensamento grego, o ente pode ainda ser visto diretamente como fenômeno, e ser visto 



do ente, é ainda um puro nomear. No enunciar, aquele que enuncia intervém, aqui o $\lambda$ ó deixa de ser $\lambda \varepsilon ́ \gamma \varepsilon ı v$ (dizer) para ser $\lambda \varepsilon \gamma o ́ \mu \varepsilon v o v$ (dito) (legomenon). No nomear, ainda posso me reportar ao ente com a nomeação tácita, mas não a partir do enunciado, porque este já é um saber sobre o "o que".

Tudo isto esclarece algo: para os gregos as coisas aparecem, para os modernos elas me aparecem, onde começa todo o sentido do que seja o reflexivo. Para Heidegger, este sentido já estava em Leibiniz, uma vez que a reflexão é um movimento de determinação da mônada, da substância. De certo modo, pode-se dizer que começa aí a reflexão da consciência sobre si mesma. Kant formulou isso em termos de justificar o que realmente se intuía, o espaço e o tempo, de modo que todas as coisas têm a forma normativa matemática de figura em movimento. Entre Aristóteles e Kant ocorreu que o ente se tornou o objeto, o oposto. Esse termo não existia para o grego, e este pensamento não tinha o ente como contraposto porque não tinha a consciência subjetiva-especulativa mirando o ente e colocando-o dentro desta fôrma. E a concepção hegeliana do Ser como sujeito absoluto, em verdade, começou no medievo, na constituição cristã do pensamento. Em um dos seus últimos seminários, Heidegger ensina (2003, p. 25):

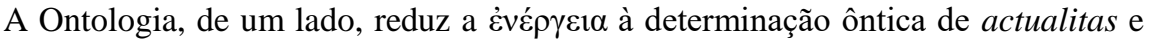
faz, por outro lado, com Tomás, do Summum Ens o Ipsum esse, suprime ipso facto toda possibilidade de questão do Ser. Toda a Filosofia moderna está sobrecarregada dessa falta ôntica que ela extrai da Ontologia cristã do Medievo. Reinstalar a Filosofia nela mesma e descarregá-la de seu elemento cristão, numa ocupação do Grego, não por ele mesmo, mas enquanto a origem da Filosofia.
\end{abstract}

Mas por que a incondicionalidade se fixou? Porque a liberdade pensada na espontaneidade da presença foi atribuída a um deus criador e este, enquanto tal, não poderia ser condicionado por nada além dele mesmo. Esse deus criador fundamentou, portanto, ainda que implicitamente (o que não foi colocado em questão antes do pensamento heideggeriano) a ideia da incondicionalidade na disponibilidade (já pressuposta pelo pensamento grego). A concretude disponibilizante é incondicional, é disponibilização incondicional. Para Heidegger isso foi o implícito fundamental que levou Descartes a pensar o sujeito fundado na incondicionalidade. Kant, Hegel e até Nietzsche retomaram implicitamente essa pressuposição, tendo este último, para Heidegger, compreendido isto enquanto vontade de

\begin{tabular}{|l|l|l|l|l|}
\hline Q Ponista & Ano 10 & n. 23 & Maio - Agosto 2021 & p. 210 - 230 \\
\hline
\end{tabular}


poder. Descartes põe a firmeza, o ente que se torna o solo, o mais concreto ao pensar a subsistência do Ser internalizando-a no sujeito; internalizada no sujeito, ela apareceu como solo firme inabalado. (Kant então pensa que, em verdade, não há a intuição da substância, mas há do espaço tempo, de modo que ficamos limitados a uma representação, mas uma representação com direito a universalidade e objetividade).

A primeira fase da questão do Ser no pensamento grego é a superabundância do ente em sua presença, a sobre-medida do ente. Eles estavam imersos nessa superabundância da presença do ente; a presença do presente era o motivo do maravilhamento, do espanto. Heidegger nos diz (2003, p.38):

É a superabundância, a sobremedida do presente. Pensemos aqui a anedota sobre Tales: ele é esse homem fascinado pela superabundância estelar, que lhe força a levar o olhar unicamente para o Céu. No clima Grego (Hölderlin, segunda carta a Böhlendorf) o homem está submergido pela presença do presente, a qual o constrange à questão do presente enquanto presente. O reporto a esse afluxo da presença, os Gregos o nomeiam Thaumázein [maravilhar-se](Cf. Teeteto, 155 d).

A Filosofia surgia exatamente deste constrangimento do presente. Este põe para o homem a imposição de pensar o presente enquanto presente. Quanto mais os gregos contemplavam, quanto mais se reportavam ao presente, mais o presente cintilava, mais luzia para eles. Já para o homem moderno, dá-se o contrário, quanto mais ele se volta para o ente nos moldes da técnica moderna, mais o ente desaparece enquanto tal. Por exemplo, quando nós contemporâneos pensamos a lua, ela já se manifesta em um fenômeno dentro do "universo estelar", cuja presença podemos explicar em uma relação causal: seu nascimento, sua massa produzida por isso e aquilo, e então: dá-se lua. Precisamente assim, a lua desaparece exatamente no seu declinar e no seu emergir. Os gregos não se reportavam para o ente formalmente, na fôrma prévia do matemático; e isso não era por alguma insuficiência de conhecimento, mas justamente porque o povo grego e todo povo fora do ocidentalismo europeu da técnico-ciência estava (ou está) reportado sem isto que Heidegger nomeia de "armação" (a tal mediação [das Gestell $\left.{ }^{3}\right]$ ). De modo que se a lua é buscada enquanto

3 No texto Die Frage nach der Technik, A Questão da Técnica (2000, p. 1-36), Heidegger nomeia a fôrma para todo o conhecimento de "armação" [das Gestell]. A armação é, para o filósofo, uma permanência implícita inquestionada para o sentido do Ser desde a qual todo conhecimento e compreensão ocidentais se fundam e se confirmam. Como é isso? Podemos exemplificar isto questionando como, por exemplo, a Natureza é pensada segundo nosso Mundo de sentido. Ela é tomada implicitamente na lida a partir da perspectiva do recurso natural. Desde a Modernidade, toda a Natureza é (implícita e inquestionavelmente)

\begin{tabular}{|c|c|c|c|}
\hline Rovista Dialectus & Ano 10 & n. 23 & Maio - Agosto 2021 \\
\hline
\end{tabular}


presença, fenômeno, nunca haveria a orientação de uma investigação meramente físicomatemática, não faria sentido.

E como então pensar o Ser enquanto ele mesmo e não mais como Ser do ente, ou a entidade do ente metafísica? Ser e Tempo é uma obra fundamental para a Filosofia porque é a etapa de destituição total da entidade do ente enquanto a subjetividade, de desarticulação do domínio da lógica sobre a questão do Ser, mas, contudo, não é a palavra final. Para este pensamento, o perceber deixa de ser um ato cognoscitivo de captura de algo, e passa a ser sustentação de reportação. Verdade é enquanto localidade do Ser, o Mundo histórico-circunscrito de sentido. “[A] 'questão do sentido do Ser'. Esta formulação foi abandonada mais tarde por essa outra de "questão da verdade do Ser" — e, finalmente pela "questão do lugar, ou da localidade do Ser" — donde o nome Topologia do Ser" (HEIDEGGER, 2003, p.46). É aí que o filósofo consegue, para o Dasein, um questionamento que o livre do lugar de consciência do homem subsistente, porque o Dasein agora é só um local e a questão se torna a de saber o que é ser um local. O que é ser esse lugar de verdade se esse lugar de verdade não é consciência subjetiva? Heidegger ensinou anteriormente que o nomear era um modo de manter o ente ainda no seu estado de fenômeno; e a enunciação, já destituía o ente do seu estado de fenômeno. Pensar o Ser por respeito ao ente (como o Ser do ente ou sua entidade) em uma representação subjetiva, implica no impedimento de pensar o Ser por respeito a ele mesmo enquanto fenômeno. Também pensar a $\alpha \lambda \eta ́ \hat{\theta} \varepsilon \imath \alpha$ por respeito ao $\lambda o ́ \gamma o \varsigma$ já implica numa limitação da $\alpha \lambda \eta ́ \theta \varepsilon ı \alpha$ por respeito a ela mesma enquanto pura e simples desocultação. Com esta explanação, Heidegger quer introduzir a problemática da

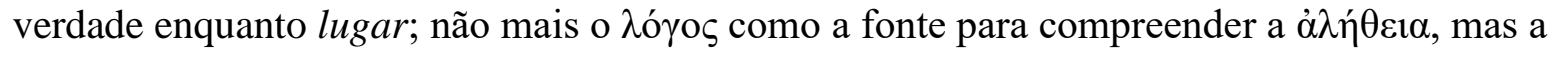
investigação da $\dot{\alpha} \lambda \hat{\eta} \theta \varepsilon ı \alpha$ enquanto $\dot{\alpha} \lambda \hat{\eta} \theta \varepsilon ı \alpha$, é que pode conceber a possiblidade do fundamento do $\lambda$ ó yos. Quando filósofo diz que o nomear não é ainda um destituir o ente da sua fenomenolidade, isto significa que, originariamente, o nomear não é ainda enunciado. Mesmo o pensamento grego vinculou o fenômeno à $\dot{\alpha} \lambda \hat{\eta} \theta \varepsilon 1 \alpha$ e a $\dot{\alpha} \lambda \eta \dot{\eta} \theta \varepsilon 1 \alpha$ ao $\lambda$ ó $\gamma o \zeta$, de modo

percepcionada no interior desta armação. A absolutamente visível desconformidade entre Dasein e Natureza no Mundo de sentido contemporâneo, se dá talvez porque há, na Natureza historicamente perspectivada enquanto mero recurso (de consumo: lazer ou contemplação), um desequilíbrio entre as possiblidades próprias da Natureza e as do Dasein. A tecnização do rio é apenas dominação. Há um rio. Como a lida compreensiva se reporta a este "hâ", esta é a questão própria do Ser. Ao questionar como está este há, Heidegger se deparou com o problema de pensar o Ser enquanto técnica.

\begin{tabular}{|c|c|c|c|c|}
\hline Rovista Dialectus & Ano 10 & n. 23 & Maio - Agosto 2021 & p. $210-230$ \\
\hline
\end{tabular}


que qualquer coisa que o pensamento faça referência, ele já faz no modo da enunciação. Mesmo Homero já se reporta ao ente dizendo o que é o ente, sobre o ente. Talvez este lugar do Ser seja ainda a linguagem poética. "Constata-se a Natureza fundamentalmente não poética do acordo grego da linguagem e, contudo, não há mais alta poesia que a grega."4

A História da Metafísica é a história do encobrimento do Ser, é o curso da história da entidade do ente, de como o Ser foi e é recoberto nessa ou naquela figura histórica. Ser e Tempo é então a única condição de se começar a investigação do Ser enquanto Ser; sem a consideração desta obra, o pensamento não tem os meios e o encaminhamento para a exposição do que é questão para pensar a História do Ser enquanto Ser. Ser e Tempo propõe todo o desmantelamento da Metafísica, coloca o Dasein no lugar de lugar da verdade e não no de consciência ou de uma subsistência; o põe no lugar de abertura, de sustentação de abertura a partir da compreensão da estrutura da analítica existencial. Considerando que não há mais o sujeito pré-determinado subsistente, e que o que há com o Dasein, é tão somente um fenômeno de ocorrência de abertura, então podemos começar a pensar o Ser enquanto Ser.

Heidegger coloca o problema da necessidade de oferecer uma contemplação do Ser e do tempo fora da perspectiva metafisica do tempo, como única forma de podermos acessar a compreensão do Ser em termos de pensamento do Ser enquanto Ser, considerada pelo filósofo importante para a compreensão da história do Ser, culminando no Ser enquanto técnica moderna. No seminário Serenidade ${ }^{5}$, o filósofo fala da potência fechada da técnica. Que potência é essa? A armação [das Gestell], a qual significa a requisição prévia que o Ser

4 Pode-se dizer que a poesia de Homero é maior do que a de Hölderlin e Mallarmé, por exemplo. Contudo estes últimos, não procediam no nomear como enunciar. Por que então Homero é mais alto? A palavra grega é a mais alta porque por mais que a poesia dos mais recentes possa ser uma poesia talvez mais radical do que a de Homero, o Mundo de Hölderlin e Mallarmé não é. Apesar das tentativas, eles não podiam mais fazer o ente se manifestar nele mesmo, porque não há a disposição própria do pensamento para isso em seu Mundo. Homero pode ter sido menor em termos poéticos, no sentido de que desviou para o enunciado, mas o Mundo homérico era o Mundo de sentido que extrapolava o limite da enunciação, porque era um Mundo divinizado, de modo que toda enunciação em Homero ainda era algo cênico, plástico. Não uma enunciação científica - embora fosse uma enunciação. Já em Hölderlin e Mallarmé, a poesia não é uma enunciação como em Homero, mas seu Mundo de sentido já é totalmente científico, de tal modo que não há a recepção possível, não há disposição [Stimmung] possível. Por isso que são poesias dificílimas de serem acessadas, sobretudo a de Mallarmé, que milita em uma linguagem não enunciativa.

5 HEIDEGGER, M. Serenidade. Tradução: Maria Madalena Andrade e Olga Santos. Lisboa, Portugal: Instituto Piaget, 2000.

\begin{tabular}{|c|c|c|c|c|}
\hline Qevista Dialectus & Ano 10 & n. 23 & Maio - Agosto 2021 & p. $210-230$ \\
\hline
\end{tabular}


faz ao homem de desafiar a Natureza em termos de mera reserva. O filósofo ensina (2003, p. 61):

\begin{abstract}
No Gestell, o homem é posto na situação de corresponder à exploração-consumo; reportação ao Ser nessa reportação. $\mathrm{O}$ homem não tem a Técnica na mão. Ele é o joguete dela. Nessa situação reina o mais completo esquecimento do Ser, a mais completa ocultação do Ser. A cibernética se torna o substituto da Filosofia e da Poesia. A Ciência política, a Sociologia e a Psicologia se tornam preponderantes, disciplinas que não têm mais o mínimo reporto ao fundamento. Nesse sentido, o homem moderno é o escravo do esquecimento do Ser.
\end{abstract}

Heidegger postula que é necessário, de certa maneira, corresponder à essa potência oculta, uma vez que já somos sempre lançados nela. Mas corresponder não significa promover; significa justamente se manter na tensão do contexto. O que Heidegger propõe para o estudioso é que ele corresponda a essa potência conquanto ele tome em questão tal potência, isto é, que ele assuma esse problema como matéria de pensamento. O pensador seria aquele que poderia orientar nesse contexto, e aquele que mediaria a posição do estudioso entre o próprio e o impróprio. Daí ele dizer que (2003, p. 43):

A este respeito o que o Senhor diz de Hebel, o amigo da casa, é significativo: "Nós hoje erramos em uma casa do mundo onde o amigo está ausente \{o Pensador\}, aquele que os seus gostos inclinam com uma força igual, para o universo tecnicamente organizado e para o mundo concebido enquanto a casa de um habitat mais original. Falta o amigo que poderia reinvestir o caráter mensurável e técnico da Natureza \{a Ciência\} no segredo aberto de um natural da Natureza a ser novamente experimentado. (ibid. p. 64). Que Pensador poderia jamais nos ajudar a reconciliar esses dois domínios tornados estranhos um ao outro e que "se distanciam um do outro a uma velocidade cada vez mais louca": a Natureza tecnicamente dirigível que é o objeto da Ciência, e a Natureza natural da estadia humana?

O "amigo" nos inclina, com a mesma força, para universo tecnicamente organizado e concebido enquanto um habitat natural. Em que sentido isso? Precisamente o sentido de que o amigo, o filósofo, nos inclina a pensar dois lugares. Eu não posso me recusar a conceber a técnica, mas também não posso me recusar a não tê-la como problema. Eu sou inclinada também para ela como necessidade de compreendê-la e, com a mesma força, sou inclinada para obter a perspectiva de um Mundo de sentido concebido enquanto uma casa, um habitat mais originário. Mas falta um amigo que possa reinserir a Ciência "no segredo

\begin{tabular}{|l|l|l|l|l|}
\hline Q & Ano 10 & n. 23 & Maio - Agosto 2021 & p. $210-230$ \\
\hline
\end{tabular}


aberto de um natural da Natureza a ser novamente experimentado.” A Natureza é, historicamente, concebida em termos de objeto da Ciência em seus sistemas causais sempre já conhecidos, e sempre em vista do seu Ser enquanto recurso e reserva. Já a Serenidade, para Heidegger, é estar postado aberto para o desconhecido, para o segredo, o oculto que se apresenta nesse Mundo dominado. E esse segredo, o que é? É a própria reivindicação histórica do Ser. Heidegger afirma que não é sem sentido essa forma de reportação técnica às coisas, o reporto técnico, uma vez que se a História (a destinação do sentido do Ser) se colocou com essa configuração, é porque justamente ela tem um sentido de ser. Esse sentido quer dizer apenas que há um sentido, isto é, há um fundamento e um direcionamento. O direcionamento, o sentido que se deu historicamente, é o da dominação e da organização das massas; e o fundamento é o próprio projeto de exploração do Todo enquanto recurso, para reserva.

"Seria necessário pensar que uma dimensão nova da essência do homem está para ser descoberta, a partir da experiência que o homem fez de seu poder sobre a Natureza?" (HEIDEGGER, 2003, p. 44). O homem da técnica não é uma nova essência. A única coisa que nos resta é querer crer que, apesar do grau de definhamento do pensamento do homem contemporâneo, essa essência não pode se perder, porque se ela se perde, acaba o homem. Se o homem da técnica se instaurar efetivamente como essência mesmo (o super-homem), acaba o Homem, porque a Natureza não suportará mais: ela mesma o exterminará de sua face. Esse projeto está desdobrado, mas não está consumado no sentido de fechado, porque a essência do homem permanece ainda "trocando as pernas". Mas no que os alunos da conferência realmente acreditam? Que há saber, que a técnica traz conhecimento do e para o Mundo. Então eles colocam a questão como se esse conhecimento pudesse apontar para algo mais radical e profundo do que a ingenuidade dos homens primordiais, os "primitivos". O sentido essencial do Mundo técnico se oculta porque precisamente se oculta o sentido da armação, porque se oculta o sentido do projeto técnico da Ciência Moderna para todo conhecimento de tudo que há. E até Heidegger, essa problemática não foi colocada. Se acredita que a Ciência Moderna é o conhecimento legítimo e real da Natureza, dos fatos, acredita-se que a técnica é um produto do homem, uma produção deste. Trata-se, portanto, de preparar a verdadeira pressuposição que essas questões expõem, que é o desdobrar da questão da essência da técnica.

Q Rovista Oialectus \begin{tabular}{l|l} 
Ano 10 & n. 23
\end{tabular} Maio - Agosto 2021 p. $210-230$ 
Devemos compreender o domínio onde a interpretação moderna da entidade do ente (Ser) aparece como posição e o conjunto dos pressupostos evidentes (inquestionados) nos quais o pensamento ocidental se move, para entender propriamente a essência histórica da possibilidade do Ser se transformar na técnica moderna e isto comandar quase que integralmente o modus operandi de nós, os homens contemporâneos. Devemos trazer o esquecimento desta questão á tona. Mas o esquecimento do Ser não é um abandono do Ser no sentido de que o Ser deixou de ser pensado; pelo contrário, o Ser, como a entidade do ente, foi cada vez mais pensado, só que pensado sobre os seus recobrimentos. Esquecimento do Ser significa dizer que o Ser enquanto Ser foi soterrado nas questões do Ser do ente. E Heidegger postula que só poderíamos compreender o sentido do Ser a partir justamente de algo contrário à entidade do ente: o (a)fundamento da ocultação. "Desde aí o Fragmento se torna: a eclosão tem por necessidade própria a ocultação. Na tradução de Jean Beaufret: "Nada é mais própria à eclosão que a ocultação" ou melhor: "Nada é mais caro a eclosão que a ocultação"” (HEIDEGGER, 2003, p. 45). Só há presença aí. Como só há manhã sobre o fundamento da Noite. A eclosão tem por necessidade própria a ocultação. Com isto Heidegger diz estar fazendo a história do fundamento da técnica por oposição ao fundamento

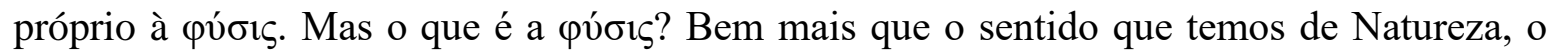

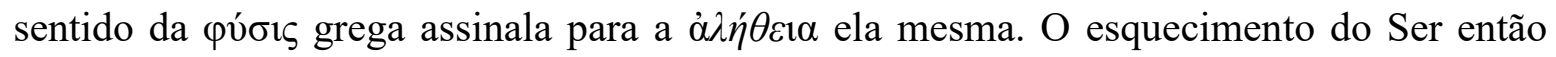
significa que a forma de compreensão da Natureza também foi se tornando cada vez mais distante e que na manifestação do Ser está implicada a ocultação; e por quê? Porque estruturalmente o Ser se determina pelo tempo. O tempo é o que propriamente realiza esse caráter de nada da ocultação, enquanto o caráter positivo da ocultação, uma vez que o tempo inclui nele precisamente o ainda-não e o já-não-mais que formam o vão do presente ${ }^{6}$.

6 Com isso Heidegger agora esclarece porque preteriu o problema do sentido: para retirar qualquer caráter subjetivista da questão do Ser. O lugar da clareira temporal do Ser ficou, em Ser e Tempo, reduzido à projeção do Dasein. No pensamento tardio do filósofo, que corresponde a estes seminários, isto muda. É um passo à frente (não para fora!). A projeção é a permanência transitiva do Dasein para o Ser. Heidegger quer somente tirar qualquer caráter subjetivista da abertura, de tal modo que o Dasein deixa de ser a própria abertura, como se acusou que estava em Ser e Tempo, pois podiam não diferenciar aquilo de consciência. Heidegger muda isso ao tirar de questão, a questão do sentido: não é mais o Dasein frente ao sentido do Ser que é o problema do Ser. Mas o que então é o sentido? Sentido é significação, e isto está sempre historicamente preso à ideia de subjetividade. É por isso que Heidegger procura substituir agora o termo sentido pelo termo verdade. Não é mais simplesmente o Dasein que se projeta para o ente, mas o Dasein aberto que pode ouvir. Estar aberto é estar aberto na escuta. E porque está na escuta, pode ser interpelado.

\begin{tabular}{|c|c|c|c|c|}
\hline Qevista Dialectus & Ano 10 & n. 23 & Maio - Agosto 2021 & p. $210-230$ \\
\hline
\end{tabular}


Nada é sem fundamento, diz Leibiniz. Nada é sem causa. Isso quer dizer que não é possível a impossibilidade de fundamento para o ente. Heidegger quer contrapor esta questão do Nada com o Nada de Hegel. Para este, o Nada se coloca como a incondicionalidade da consciência, uma vez que esta não é condicionada por nada. Ser é nada no sentido da incondicionalidade; mas esta incondicionalidade é derivada da entidade do ente enquanto Sujeito moderno. A questão para Heidegger é, portanto, a de compreender o Ser na perspectiva da Metafisica onde o Ser é posto como entidade do ente (fundamento), finalmente se desdobrando como a incondicionalidade da consciência em Hegel, para depois compreender a questão do Nada como lugar de possibilidade de uma clareira. Talvez aí consigamos fazer um apanhado histórico do Ser na perspectiva de toda a Metafísica, o que culmina tanto no Ser enquanto a técnica moderna quanto na perspectiva do pensamento do Ser ele mesmo, isto é, do último pensamento do Ser enquanto o Acontecimento [das Ereignis].

No fim da Metafísica, a Lógica significa ciência, ontologia, e é o que Hegel denomina como “os pensamentos de deus antes da criação”. Heidegger nos diz (2003, p. 48):

Que reporto pode haver entre o Ser e o Nada em Hegel e a formulação a qual chega o reconhecimento extra-metafísico da diferença ontológica como fonte oculta da Metafísica? Para abordar esta questão, o Seminário se interroga então sobre o lugar onde, no Pensamento de Hegel, se encontra a proposição dita acima. Ela se encontra no início da Lógica. Esta aqui é na verdade intitulada Ciência da Lógica (Saber [em sua estrutura orgânica] da lógica). A proposição fala desde o horizonte desde o horizonte de um Saber (que Hegel imagina dizendo que se trata dos pensamentos de Deus antes da criação).

É ciência da lógica porque a consciência, para toda a Metafísica, a partir de Descartes, tem a forma da razão. A razão é um pensamento de configuração lógica; e ciência da lógica quer dizer ciência do pensamento. A ciência da consciência tem a forma da lógica, pois o comportamento da consciência é o de associação de ideias segundo princípios - uma regra da lógica. Quando Hegel fala em ciência da lógica ele fala em ciência da consciência. E porque a ciência da lógica é, para Hegel, a ciência da consciência, ele pode dizer que são 
pensamentos de deus antes da criação, porque é o saber do a priori. É o saber da compreensão pré estabelecida para todo e qualquer concreto, todo e qualquer ente. ${ }^{7}$

Dissemos que desde Descartes a questão da verdade se configura como certeza. De modo que a questão do fundamento pede uma fundamentação para que aquele fundamento seja garantido como fundamento. A questão do a priori se desloca para o âmbito da consciência, e a absolutização do cogito cartesiano se dá no saber absoluto.

O absolutismo da consciência coloca o homem tanto do pensamento filosófico, quanto científico, religioso e pré-filosófico, como o Senhor do Todo. Tudo deve servi-lo: o conhecimento, o outro, a Natureza. Esta iluminação quer dizer: a implícita e cotidiana clareza de sentido, a implícita e cotidiana clareza de compreensão. Heidegger nos $\operatorname{diz}(2003$, p. 60):

O modo dessa destinação é a Objetidade [Gegenständlichkeit] (enquanto o serobjeto do objeto). Ora quanto mais a Técnica moderna se desdobra, tanto mais a ob-jetidade [Gegen-ständlichkeit] se transforma em reserva [Beständlichkeit] (ater-se à disposição). Hoje já não mais objetos [Gegenstände] (o ente enquanto ele se atém postado frente a um Sujeito que o toma em vista) - não há mais senão reservas [Bestände] (o ente que se atém pronto para ser consumido); em português poder-se-ia talvez dizer: não há mesmo mais substâncias, mas apenas subsistências no sentido de "reservas". Donde as políticas de energia e de planejamento territorial, as quais não têm mais afazer com objetos, mas, no interior de uma planificação geral, põem em ordem sistematicamente o Espaço em vista de uma planificação futura.

O Ser se oferece como reserva e o meu existir lançado no Mundo compreende imediata e pré-ontologicamente a significação Ser como reserva. Qualquer criança hoje na escola e na vida apreende isso pré-ontologicamente, sem que ninguém verbalize diretamente. No Mundo impessoal, você vale se você reserva. Heidegger quer com isso apontar que, embora a língua esteja nesse processo de decadência (onde o Ser interpela o Dasein prétematicamente como reserva e é compreendido implícita e necessariamente como reserva), deu-se uma brecha em Ser e Tempo, no momento em que o filósofo foi perguntar o que é o

7 Já a compreensão do Ser heideggeriana se dá em uma estrutura que implica um comportamento ôntico: o ser-no-mundo não é de modo algum um a priori formal. Há fenômenos concretos implicados na constituição do Ser como: ser-no-mundo, ser-para-a-morte, temporalidade e a cura. Esses momentos estruturais da compreensão do Ser não são formas lógicas, são existenciais, são fenômenos. Então, pensar a compreensão do Ser como a priori não pode ser pensar este como algo formal da lógica, pois este não tem forma e conteúdo: ele é dado pelo empírico.

\begin{tabular}{|c|c|c|c|c|}
\hline Rovista Dialectus & Ano 10 & n. 23 & Maio - Agosto 2021 & p. $210-230$ \\
\hline
\end{tabular}


Ser. Pela primeira vez na história do pensamento ocidental, a questão que se pôs não era a de saber o que seria o Ser do ente, mas simplesmente o que é Ser. E quando essa questão "o que é Ser?" entrou como problema, apareceu o Ser interpelando o Dasein enquanto técnica e reserva. Se Heidegger não tivesse perguntado o que é Ser, se tivesse perguntado, como toda a Metafísica, sobre o que é o ente, ou sobre o Ser do ente, ele não poderia radicalmente saber que o Ser estava se apresentando como reserva. Essa foi talvez a primeira "espetada" concreta de um pensamento ocidental na Metafísica, o primeiro golpe de peso. Quando o Ser começou a ser problematizado como questão por ele mesmo a parte do ente, aí o Ser pôde aparecer como isso que nos interpela, e que nos interpelando na forma em que nos interpela, dirige a nossa compreensão integralmente. O Ser nos interpela como Mundo histórico-circunscrito de sentido, isto é, isso que nos interpela como o que está estabelecido de sentido aí no Mundo dirige a compreensão do Dasein cotidiano.

Heidegger trata do problema da possibilidade de uma mudança no contexto histórico do pensamento a partir de uma mudança na estrutura da linguagem. "Estando bem entendido que não é em dez ou vinte anos que se pode pôr de lado uma herança bimilenar. Ao invés disso a Filosofia de hoje se limita a correr atrás da Ciência, no desconhecimento das duas únicas realidades da época presente: o desenvolvimento econômico e o aparelhamento que o requer”. (HEIDEGGER, 2003, p. 51). A linguagem, segundo o filósofo, está se transformando em pura informação. Ela está sendo apreendida na perspectiva da operacionalidade calculadora da informação. O filósofo postula (2003, p. 50):

Roger Munier observa que é com efeito um caráter essencial das linguagens da informática o constituir por agrupamento de tudo, a partir de uma análise reducionista, uma estrutura nova e absolutamente pobre disso que funcionará doravante enquanto essência da linguagem em todas as operações técnicas. A linguagem é assim decapitada e reduzida imediatamente em conformidade à máquina. É claro que um reporto à linguagem que torna possível um tal fenômeno é a compreensão desta aqui como simples instrumento de informação.

Dá-se notícias da Natureza, não há mais a pretensão de descrevê-la em sua genesis, em seu Ser. A Física contemporânea trata qualquer problema como se já sempre fosse conhecido se debruçando nas relações que pode estabelecer com ele. Tudo que a Física sabe do movimento, ela tem questão do que é possível fazer valer com a manipulação das formas do movimento. Ela oferece um novo reporto à Natureza que é a nova pretensão da

\begin{tabular}{|c|c|c|c|c|}
\hline Rovista Dialectus & Ano 10 & n. 23 & Maio - Agosto 2021 & p. $210-230$ \\
\hline
\end{tabular}


Física de produção do homem. "O importante, acrescenta Heidegger, é compreender que a Física não pode dar o salto para fora dela mesma" (HEIDEGGER, 2003, p. 54).

A destinação final da Metafísica nos séculos XIX e XX foi a do Ser enquanto objetividade. E quanto mais a técnica moderna se desdobra, tanto mais a objetidade do objeto, que significava conhecimento, se transforma em reserva, significando acúmulo e apenas a plena disponibilidade. Para Heidegger toda ciência moderna já é uma produção da técnica, porque a técnica na sua essência configura um propósito de abordagem pré-temático específico da Natureza. Antes, a subsistência do Ser, a entidade do ente, era pensada para o conhecimento enquanto conhecimento; algo é permanente, subsistente, aí disponível para a abordagem investigativa - e foi assim desde Platão. Agora algo é permanente não mais no sentido de qualquer busca ou produção de verdade, de conhecimento, mas no sentido simplesmente de algo tem que estar sempre aí disponível, e descartável de preferência. A partir dessa experiência de nosso tempo, Heidegger diz (2003, p. 60-61):

Ora um dos momentos essenciais desse modo do Ser do ente contemporâneo (a disponibilidade para um consumo planificado) é a substituibilidade, o fato que cada ente se torna essencialmente substituível, em um jogo generalizado onde tudo pode tomar o lugar de tudo. Isso é o que manifesta empiricamente a indústria de produtos de "consumo" e o reino do descartável. Ser, hoje, é ser-substituível. A ideia mesmo de conserto se tornou uma ideia "anti-econômica". A todo ente de consumo é essencial que ele seja já consumido e chamado, assim, à sua substituição. Nós temos aí uma das faces do desaparecimento do tradicional, disso que se transmite de geração em geração. Mesmo no fenômeno da moda, o essencial não é o adorno (a moda se tornou, assim, enquanto adorno tão anacrônica quanto o conserto), mas a substituibilidade dos modelos de estação em estação. A roupa não é mais trocada quando e porque se tornou defeituosa, mas porque ela tem o caráter essencial de ser "a veste do momento à espera da seguinte".

Isso ocorre de tal modo que a própria ideia de subsistência mudou: o que deveria ser sempre o mesmo para a investigação, agora deverá ser sempre o substituível: é ainda o mesmo, mas o mesmo enquanto o que permanece como sempre já substituível. Esse mesmo era em vista do conhecimento, em vista do Ser enquanto ideia, pensamento, mas a questão não é mais a de conhecer: o que foi fornecido durante dois milênios de ideia já basta. E por isso as investigações científicas não descobrem, elas não têm mais o ente para conhecer: elas já têm todos os pressupostos e repetem-os em cada pesquisa. O que a ciência da técnica consegue, é compilar características que ela já tem como estrutura de conhecimento; e o que

\begin{tabular}{|l|l|l|l|l|}
\hline Qovista Dialectus & Ano 10 & n. 23 & Maio - Agosto 2021 & p. 210 - 230 \\
\hline
\end{tabular}


escapa a isso permanece fora de questão, porque não sabemos mais fazer conhecimento do Ser de algo.

O conhecimento agora é pura e simplesmente conhecimento de ordenação e planificação, isto é, de trato com reserva. O Ser do ente não é mais questão. Com isso Heidegger ensina (2003, p. 60):

Tudo (o ente no todo) toma lugar de imediato no horizonte da utilidade, do comando, ou melhor, do patrocínio disso do qual é preciso se assenhorar. A floresta cessa de ser objeto (o que ela era para o homem científico dos séculos XVIII e XI) e se torna para o homem, enfim desmascarado enquanto técnico, isto é, o homem que visa o ente a priori no horizonte da utilização, o "espaço verde". Nada mais pode aparecer na neutralidade objetiva de um face a face. Não há mais nada que reserva.

A Natureza que experimentamos é o espaço verde para o meu consumo ou lazer e/ou reserva, de modo que mesmo a questão do em si moderna não compete mais. Não mais a constancialidade, mas a requisitabilidade, a possibilidade de a Natureza ser comandada, de estar permanentemente somente à disposição para uso. Na requisitabilidade o ente é posto como fundamentalmente disponível para consumo. E esta requisitabilidade tem sua raiz há dois mil anos no pensamento grego, contudo tal requisitabilidade não era vista meramemente em vista do consumo. A ideia da superabundância da presença era $o$ problema. Se tornou puro consumo uma vez que o homem enquanto o Sujeito índice de determinação de todo o real, foi colocado como a lei, como o diretor do saber, o fundamento inquestionável, e o Ser requereu o homem nessa perspectiva. O Ser foi pensado como presença na disponibilidade desde o pensamento grego, mas não havia o eu como diretor; contudo, podemos pensar que este acaba sendo uma consequência possível daquele.

A disponibilidade do ente para o consumo planificado é uma outra forma de demanda da disponibilidade, portanto: a subsistubilidade. O Ser contemporâneo é o ser substituível, é ser objeto de consumo. Isso quer dizer que, aos poucos, o homem vai perdendo cada vez mais a compreensão do ente, porque não há mais o aprendizado próprio do ente, não há mais tradição: o aprendizado que está sendo empegado é no sentido de produzir consumo. O ente cada vez mais é menos inquirido no seu Ser, até porque como ele é descartável, não tem porque conhecer seu Ser, porque seu Ser é apenas o substituível. 
A ideia de presença na perspectiva da Metafísica, da armação, dá esse caráter de atualidade, pois a renovação tem que estar atual. Por isso Heidegger nos ensina acerca dessa forma de nosso Ser histórico (2003, p. 61):

No Gestell, o homem é posto na situação de corresponder à exploração-consumo; reportação ao Ser nessa reportação. O homem não tem a Técnica na mão. Ele é o joguete dela. Nessa situação reina o mais completo esquecimento do Ser, a mais completa ocultação do Ser. A cibernética se torna o substituto da Filosofia e da Poesia. A Ciência política, a Sociologia e a Psicologia se tornam preponderantes, disciplinas que não têm mais o mínimo reporto ao fundamento. Nesse sentido, o homem moderno é o escravo do esquecimento do Ser.

O homem se reporta ao Ser nessa forma de reportação. E o Ser se dá ao esquecimento, completamente. Mas o Ser também tem seus limites, porque se o Ser destrói o homem se ocultando, também fica sem abertura de possibilidade de manifestação. Que o Ser, portanto, não possa ser absolutizado a partir de si: eis a antítese a mais aguda por respeito a Hegel, pois o Ser para Hegel é absolutização a partir de si próprio, da própria consciência. 'Ele [Hegel] não o diz senão em eco ao cristão 'Deus tem necessidade dos homens'. Para o Pensamento de Heidegger, ao contrário, o Ser não é sem o seu reporto ao Dasein $^{8}$. Nada mais distante de Hegel e de todo o Idealismo”. (HEIDEGGER, 2003, p. 61) O Ser não é algo antes que se reporta ao Dasein como o Deus de Hegel.

Historicamente instaurou-se na Modernidade a figura do sujeito, do agente do conhecimento. A ideia da Ciência no princípio da Modernidade era a ideia da produção do saber rigoroso em vista da obtenção dos segredos do comportamento da Natureza para a dominação da mesma. Conseguindo isso como uma grande enciclopédia de saber da Natureza não se precisou mais saber da Natureza: agora é operar com esse saber. A técnica não quer do saber, nada além disso. Ela não precisava mais nem do sujeito nem do objeto. Conhecer a Natureza não era mais interesse da técnica, seu interesse passou a ser agora o de compreender os meios de uma planificação do sabido para dominação, ordenação e manipulação desse sabido enquanto recurso, para reserva. Lá nos gregos, a ideia de saber os segredos da Natureza era para ter os meios de obter energia da Natureza; agora é como usar essa energia em vista da própria manipulação de todos os recursos da Natureza,

\footnotetext{
8 "Mais original que o homem é a finitude do Dasein nele". HEIDEGGER, Martin. Kant e o Problema da Metafísica. Tradução: Alexandre Franco de Sa \&| Marco Antônio Casanova. Rio de Janeiro-RJ: Editora Via Verita, 2019, p. 285.

\begin{tabular}{|l|l|l|l|l|}
\hline Q Rovista Dialectus & Ano 10 & n. 23 & Maio - Agosto 2021 & p. $210-230$ \\
\hline
\end{tabular}
}


fundamentalmente o recurso principal, o homem: os "recursos humanos", onde somos nada além de reserva, e recurso de relação comercial. Com o predomínio do projeto da técnica que, segundo Heidegger, dissolveu sujeito e objeto na figura do recurso, ou seja, a natureza é apenas recurso e reserva; e recurso em vista do desenvolvimento econômico absolutamente incondicional. Em vista dessa transformação, a Natureza que já tinha perdido seu caráter próprio na fase sujeito-objeto, se tornou um sistema de causa e efeito, um sistema causal de produção de fenômenos. Quando esses fenômenos já estão todos mapeados nas suas possibilidades, a Natureza deixa de ser Natureza para ser recuso puro e simples, onde o rio não é mais rio, e sim usina de energia, onde o solo é zona de mineração, a floresta é área de recurso de madeira, e o verde se torna espaço verde no sentido puro e simples de lugar de turismo, de recurso para este, recreação, indústria farmacêutica, agropecuária, etc. A Amazônia é fonte para servir à indústria de medicação, da madeira, remédio, alimento; o solo dá ouro, nióbio, petróleo. É isso que é Natureza. Esta não nem mais nem mesmo o sistema causal como dentro da Física antiga ou moderna. Conhecimento agora é somente o de saber como podemos usurpar e acumular. Este é agora como um princípio normativo implícito. Esse momento da técnica é um momento de instauração da consumação da Metafísica em linguagem de informação. Cibernética, que é a linguagem que permite a transmissão plena do totalitarismo implícito nesse modelo. Essa linguagem da informação constitui a estrutura desse tipo de saber, permite que esse saber se convalide em todos os âmbitos.

\section{Referências}

HEIDEGGER, Martin. Conferências e Escritos Filosóficos. Tradução de Ernildo Stein. São Paulo-SP: Abril Cultural, 1996.

. Grundbegriffe der Aristotelischen Philosophie. Gesamtausgabe Band 18. Vittorio Klostermann GmbH: Frankfurt am Main, 2002.

. Introdução à Metafísica. Tradução de Mário Matos e Bernhard Sylla. Lisboa: Instituto Piaget, 1997.




Kant e o problema da Metafísica. Tradução: Alexandre Franco de

Sa \&| Marco Antonio Casanova. Rio de Janeiro-RJ: Editora Via Verita, 2019.

Sein und Zeit. 17a Aufl. Tübingen. GA Band 2. Max Niemeyer Verlag GnbH e Co. 2006.

. Os Problemas Fundamentais da Fenomenologia. Tradução de Marco Antônio Casanova. Petrópolis-RJ: Editora Vozes, 2012.

. Serenidade. Tradução: Maria Madalena Andrade e Olga Santos. Lisboa: Instituto Piaget, 2000.

. Thor Seminaries. Translated by: Andrew Mitchell and François Raffoul. Indiana-USA: Indiana University Press, 2003. 